\title{
Green analytical method for quantification of Secnidazole in tablets by Fourier- Transform Infrared Spectroscopy (FTIR)
}

\author{
Jéssica Gonçalves de Souza Lima ${ }^{\mathrm{a}^{*}}$, Bianca Aparecida de Marco ${ }^{\mathrm{a}}$ and Hérida Regina Nunes Salgado ${ }^{\mathrm{a}}$
}

${ }^{a}$ Department of Pharmaceutics, School of Pharmaceutical Sciences, Universidade Estadual Paulista, Rodovia Araraquara-Jaú, km 1, CEP 14800-903, Araraquara, SP, Brazil.

*Corresponding author: jesouzalima94@gmail.com

\begin{abstract}
Secnidazole is a medicine widely used in the treatment of bacterial and protozoal diseases. The free sale of this drug allows its easy access to the population and for this reason, the studies that involve the analysis of the quality control of this drug are extremely important to keep the results safe and reliable. Considering the great pharmacotherapeutic application of secnidazole and the great importance of developing new analytical methods that contribute to the environment, the study was based on the development and validation of a new sustainable analytical method by Fourier-transform infrared spectroscopy (FT-IR) to identify and quantify secnidazole tablets. The method was validated according to the ICH guidelines, presenting precision, accuracy, selectivity, robustness and linearity in the concentration range of $0.5-1.3 \mathrm{mg} / \mathrm{pellet}$. The application of this method in addition to being safe and reliable is highly favorable from an economic point of view since that present speed analysis, lower economic costs and significant reduction of the solvents with minimal or no pre-treatment in the samples, being fast and simple and can also be applied to other medicines.
\end{abstract}

Keywords: infrared spectroscopy, green chemistry, secnidazole, validation

\section{Introduction}

Secnidazole (Figure 1) is a drug with broad-spectrum activity against anaerobic protozoa and many anaerobic and microaerophilic bacteria which belongs to the group of 5nitroimidazoles, it is chemically designated, according to IUPAC, as (RS) -1- (2-methyl-5-nitro-1H-imidazol-21-yl) propan-2-ol (1).

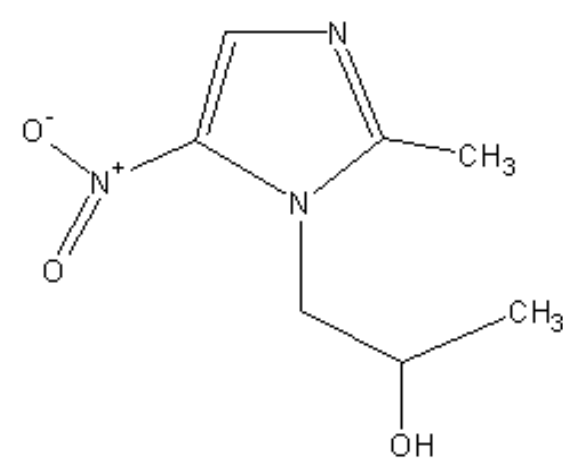

Figure 1. Chemical structure of secnidazole (CAS 3366-95-8).

The nitro group in its chemical structure leads to the action of the drug when it suffers a reduction after the drug penetration by microorganism diffusion. In the case of parasites, such reduction occurs by the pyruvate-ferridoxin pathway (2).

In the literature, it was found many analytical methods for the quantification of secnidazole by HPLC (3-9) and UV-Vis spectroscopy (10-13). However, these methods use large quantities of toxic solvents, buffer solutions in mobile phase and production of high levels of waste, which is not interesting for environmental preservation and because they are against the principles of green analytical chemistry.

In the literature, the IR spectroscopy is considered an excellent method for identification of drugs and pharmaceutical medicines, but recent studies demonstrate that this technique also can be used for quantification of substances. It contemplates the green chemistry because it only uses potassium bromide as reagent, promoting advantages as low cost, low generation of toxic waste and no use of organic solvents (14). IR technique also have others advantages as low analysis time, simplicity in the execution and possibility of the analysis of insoluble material in the commonly used solvents for preparing solutions for another analysis techniques (15).

Fourier-transform infrared spectroscopy (FT-IR) is a technique widely used by industries and laboratories because it is more sensitive and faster than the dispersive infrared spectrometer, because it measures energy at one time absorbed to sample at each wavelength through a beam of transmitted infrared light. (16-28).

Thus, the purpose of our paper is to develop and validate a new analytical method for quantification of secnidazole in tablet using the infrared technique and contributing to the drug quality control by introducing an environmentally friendly method.

\section{Experimental}

\section{Chemicals and reagents}

Secnidazole reference chemical substance (RCS) with purity content of $99.63 \%$ and sample (tablets containing $1.000 \mathrm{mg}$ 
secnidazole) were kindly provided by the EMS pharmaceutical company (Hortolândia, SP, Brazil).

Potassium bromide (BrK) (Synth, Brazil) used for pellets preparation was analytical grade. To obtain the pellets, $\mathrm{BrK}$ was powdered and dried to constant weight at $105^{\circ} \mathrm{C}$.

\section{Equipment}

An FT-IR spectrometer (Shimadzu®, Kyoto, Japan, IR Prestige-21 model) was used to obtain the spectrums in the region of $4000-500 \mathrm{~cm}^{-1}$ at intervals of $2 \mathrm{~cm}^{-1}$. The band corresponding to nitro group in the molecule of drug was selected using the support of IR Solution software, which was consisted in the spectral region between $1560-1350 \mathrm{~cm}^{-1}$.

\section{Obtaining of analytical curve}

Equivalent amounts of $0.5,0.7,0.9,1.1$ and $1.3 \mathrm{mg}$ of secnidazole were previously diluted in $\operatorname{BrK}(1: 10 \mathrm{w} / \mathrm{w})$ and after this, the samples were diluted in BrK again to obtain enough quantities of $150 \mathrm{mg}$ of pellets. After adding the powders, the homogeneous mixture was submitted to mechanical pressure of $85 \mathrm{kN}$ for 10 minutes, to prepare translucent pellets.

\section{Preparation of secnidazole RCS pellets}

Aliquots of powder equivalent to $0.9 \mathrm{mg}$ of secnidazole RCS were diluted with $\mathrm{BrK}$ in a ratio of $1: 10(\mathrm{w} / \mathrm{w})$ and after this, the mixture were properly homogenized in $141 \mathrm{mg}$ BrK to form translucent pellets of $150 \mathrm{mg}$. The determinations of the substance were performed in triplicate and the readings were performed in absorbance.

\section{Preparation of secnidazole tablets pellets}

First, the mean weight of twenty tablets of secnidazole $1 \mathrm{~g}$ was determined according to the Brazilian Pharmacopoeia, 2010 (29). Aliquots equivalent to $0.9 \mathrm{mg}$ secnidazole were weighed and diluted with $\mathrm{BrK}$ in a ratio of $1: 10(\mathrm{w} / \mathrm{w})$ and after this, were homogenized in $141 \mathrm{mg} \mathrm{BrK}$, to form translucent pellets of $150 \mathrm{mg}$. The determinations of the substance were performed in triplicate and the readings were performed in absorbance.

\section{Preparation of adjuvants present in secnidazole tablets}

A mixture of adjuvants present in the tablets of secnidazole was performed in the usual concentrations to assess the possibility of interference in spectrophotometric analysis of secnidazole in the infrared region. All the adjuvants, being microcrystalline cellulose, maize starch, hypromellose, purified water, polyethylene glycol, sodium starch glycollate, povidone, magnesium stearate, colloidal anhydrous silica and isopropyl alcohol, were homogenized and diluted 1:10 in BrK for the formation of pellets of 150 $\mathrm{mg}$. The determinations of the substances were performed in triplicate and the readings were performed in absorbance.

\section{Method validation}

The method was validated according to the International Conference on Harmonisation guidelines showing: accuracy, linearity, precision, robustness, selectivity and limits of detection and quantification.

\section{Linearity}

To validate the method, it was used five concentrations $(0.5$, $0.7,0.9,1.1$ and $1.3 \mathrm{mg}$ ) of secnidazole to obtain the curve. The linearity of the method was evaluated by linear regression analysis, which is calculated by the square minimum method and the statistical analysis was by ANOVA. The linearity was carried out in three days.

\section{Selectivity}

The selectivity of the method was performed to certify whether the presence of the adjuvants present in the secnidazole tablets were not able to interfere in the quantification of the drug. For this parameter, the measurements were performed in triplicate and the spectra were overlapping.

\section{Precision}

The precision of the method was obtained by two different criteria: repeatability (intraday precision) and intermediate (interdays precision and between analyst precision).

The repeatability precision was performed with the preparation of six secnidazole pellets at a concentration of $0.9 \mathrm{mg} / 150 \mathrm{mg}$ pallets, on the same day and under the same working conditions. The intermediate precision (interdays) was carried out by the same analytical conditions to repeatability, but in three different days and the intermediate precision (between analysts) was performed by another analyst, but under the same working conditions, which were calculated by the relative standard deviation (RSD), ANOVA and student's $t$-test respectively.

\section{Accuracy}

Accuracy was evaluated according to the recovery test in which known amount of standard was added in known quantity of sample (ICH, 2005) in three concentration levels (R1, R2, R3), which were performed in triplicate on three different days. Table 1 shows the preparation of the tablets for the recovery test method.

Table 1. Preparation of pellets for the test of recovery of FT-IR method for secnidazole.

\begin{tabular}{|c|c|c|c|c|c|}
\hline & $\begin{array}{c}\text { Secnidazole } \\
\text { sample (mg) } \\
\text { (dilution } \\
1: 10, \text { w/w in } \\
\text { BrK) }\end{array}$ & $\begin{array}{c}\text { Secnidazol } \\
\text { e standard } \\
\text { (mg) } \\
\text { (dilution } \\
1: 10, w / w \\
\text { in } \mathrm{BrK} \text { ) }\end{array}$ & $\%$ & $\begin{array}{c}\text { Final } \\
\text { theorical } \\
\text { concentration } \\
\text { (mg/pellets) }\end{array}$ & $\begin{array}{c}\text { BrK } \\
\text { amount } \\
(\mathrm{mg})\end{array}$ \\
\hline Sample & 0.50 & --- & & 0.50 & 145.00 \\
\hline R1 & 0.50 & 0.22 & 80 & 0.72 & 142.80 \\
\hline R2 & 0.50 & 0.40 & 100 & 0.90 & 141.00 \\
\hline R3 & 0.50 & 0.58 & 120 & 1.08 & 139.20 \\
\hline Standard & --- & 0.50 & & 0.50 & 145.00 \\
\hline
\end{tabular}




\section{Robustness}

This parameter is important to show that the validity of the method is maintained even with small variations in the method 's working conditions. For evaluation of the robustness, individual modifications were made to the established experimental conditions, such as: the potassium bromide (BrK) source, the compression time and the compression strength to produce the pellet. The obtained responses were statistically analyzed using student's $t$-test to evaluate the effects of the modifications.

\section{Detection and Quantitation limits}

The limits of detection and quantification were based and calculated according to the standard deviation and intersection curve that were obtained from three different curves. The values were calculated using the Equations 1 and 2.

$$
\begin{aligned}
& \text { Equation 1. } L O D=3.3 \times S D \div a \\
& \text { Equation 2. } L O Q=10 \times S D \div a
\end{aligned}
$$

Where: $\mathrm{a}=$ inclination of the analytical curve. $\mathrm{SD}=$ intercept standard deviation.

\section{Results and discussion}

Research and analysis focused on quality control of medicines are extremely important, because it is through them that the results will guarantee the effectiveness and quality of the final products. Quality control aims to identify the physical, chemical and biological properties of the active products adopting processes and procedures through equipment, materials and systems developed (30-32). Along with this and taking in account the reduction of environmental impacts and the safety of operators and patients, the industries would choose to invest in ecologically correct methods, such as infrared (IR) spectroscopy.

In IR spectroscopy technique, the molecule when absorbed, presents frequency by infrared radiation absorbing natural vibrational frequency, which originates in an increase of the amplitude of this vibration movement in the chemical bonds of molecules (28).

Numerous analytical methods have been found in the literature to identify and quantify secnidazole, but the methods present some disadvantages when it comes to the application of green chemistry methods because they use more expensive reagents, toxic solvents, slower production processes and analyzes and generation of toxic waste (3337).

Besides FTIR method do not use organic solvent, it presents others advantages as easy implementation, speed the analysis, lower economic cost, minimal or no pre-treatment in the samples, allowing the presence of impurities when present in the samples and providing optimal resolution and accurate results in quantitative and identification analysis, especially in drugs and/or substances that present incompatibilities with solvents $(16,19,20,26)$.

Thus, an innovative infrared spectroscopy method for the analysis of secnidazole tablets was developed and validated, due to non-use of the organic solvent, allowing a reliable quantification of secnidazole tablets, being an excellent alternative method to the routine of quality control in laboratories and pharmaceutical industries.

The method can be quantified by measuring the absorbance of the band corresponding to the nitro group presents in the drug molecule, in the region between 1.560 and $1.350 \mathrm{~cm}^{-1}$, showing accuracy, linearity, precision, robustness and selectivity.

\section{Linearity}

The analytical curve was made on three consecutive days, showing mean values of absorbances in the region of 1560 $1350 \mathrm{~cm}^{-1}$ in relation to concentrations between 0.5 to 1.3 $\mathrm{mg} /$ pellet as shown in Figure 2. The correlation coefficient (r) was of 0.9985 and statistical analysis (Table 2) was calculated by ANOVA and the calculated showed $(p<0.05)$, F calculated (3.34) lower than F critical (3.71), showing the linearity of the method (38).

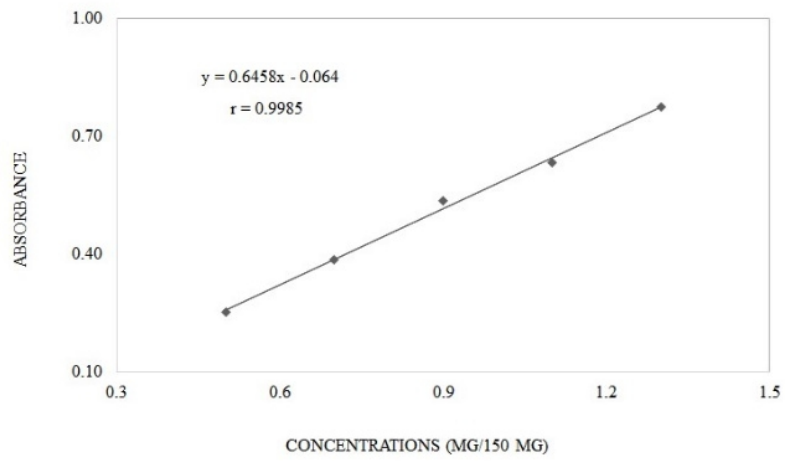

Figure 2. Graphical representation of the analytical curve of secnidazole by FT-IR method.

Table 2. Analysis of variance (ANOVA) of the linearity using FTIR for determination of secnidazole.

\begin{tabular}{lccccc}
\hline \multicolumn{1}{c}{$\begin{array}{c}\text { Source of } \\
\text { variation }\end{array}$} & DF & $\begin{array}{l}\text { Sum of } \\
\text { Square }\end{array}$ & Variance & $\begin{array}{c}\text { F } \\
\text { calculated }\end{array}$ & $\begin{array}{c}\text { F } \\
\text { critical }\end{array}$ \\
\hline $\begin{array}{l}\text { Between } \\
\text { concentrations }\end{array}$ & 4 & 0.50205 & 0.12551 & $492.85^{*}$ & 3.48 \\
$\begin{array}{l}\text { Linear } \\
\text { regression }\end{array}$ & 1 & 0.49950 & 0.49950 & $1961.39^{*}$ & 4.96 \\
$\begin{array}{l}\text { Linear } \\
\text { deviations }\end{array}$ & 3 & 0.00255 & 0.0008494 & 3.34 & 3.71 \\
Residue & 10 & 0.00255 & 0.0002547 & - & - \\
Total & 14 & 0.50460 & - & - & - \\
\hline
\end{tabular}

\section{Selectivity}

The adjuvants present in the tablets of secnidazole did not show specific absorption bands. Thus, there is no interference with the results obtained for the quantification of the drug, as shown in Figure 3. 
Drug Anal Res, 2018; 02, 14-19

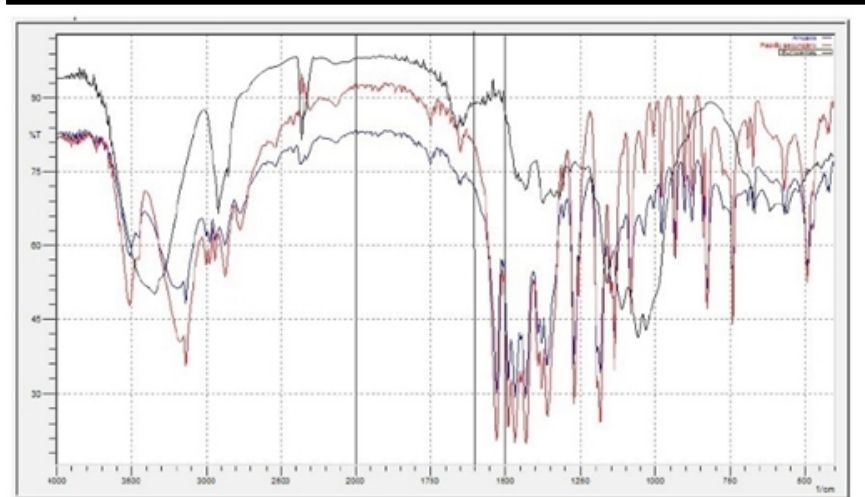

Figure 3. Overlap absorption spectra in the infrared region secnidazole CRS (in red), secnidazole tablets (in blue) and adjuvants (in black).

\section{Precision}

The repeatability precision of the analytical method was considered reliable due the value obtained of RSD have been low $(<5.0)$. The intermediate precision (interdays and between analysts) was performed by two analysts, ANOVA and student's $t$-test, respectively, and comprove the precision of the method due the values calculated of $t$ or $\mathrm{F}$ were lower than the values critical of $t$ or F. The results found for the precision parameter are presented in Table 3.

Table 3. Determination of the precision of the FT-IR method for analysis of secnidazole.

\begin{tabular}{ccc}
\hline Repeatability & \multicolumn{2}{c}{ Intermediate } \\
Intraday & Interdays precision & $\begin{array}{c}\text { Between analyst } \\
\text { precision }\end{array}$ \\
Average $=$ & & Test $\mathrm{F}$ \\
$0.464^{*}$ & $\mathrm{~F}_{\text {calc }} 1.48<\mathrm{F}_{\text {crit }} 3.10$ & $\mathrm{~F}_{\text {calc }} 1.29<\mathrm{F}_{\text {crit }} 5.05$ \\
& Valor- $P=0.26$ & Test $t$ \\
RSD $(\%)=$ & $t_{\text {calc }} 1.11<t_{\text {crit }} 2.22$ \\
$2.56^{* *}$ & & \\
& &
\end{tabular}

*Average of six determinations **Relative Standard Deviation of six determinations

\section{Accuracy}

The accuracy was carried out by recovery test that presented adequate values, obtaining rates very close to $100 \%$ recoveries, showing the accuracy of the method. Table 4 shows the data obtained in the recovery test.

Table 4. Determination of the accuracy of the FT-IR method for analysis of secnidazole.

\begin{tabular}{cccccc}
\hline & $\begin{array}{c}\text { Secnidazole } \\
\text { SCR } \\
\text { added } \\
\text { (mg) }\end{array}$ & $\begin{array}{c}\text { Secnidazole } \\
\text { SCR } \\
\text { founded } \\
\text { (mg) }\end{array}$ & $\begin{array}{c}\text { Recovery } \\
\mathbf{( \% )}\end{array}$ & $\begin{array}{c}\text { RSD } \\
\text { (\%) }\end{array}$ & $\begin{array}{c}\text { Average } \\
\text { recovery } \\
\text { (\%) }\end{array}$ \\
\hline R1 & 0.220 & 0.219 & 99.93 & 1.59 & \\
R2 & 0.440 & 0.399 & 99.99 & 1.60 & 99.53 \\
R3 & 0.580 & 0.572 & 98.66 & 0.48 & \\
\hline
\end{tabular}

\section{Robustness}

The effects of each modification in the potassium bromide (BrK) source, the compression time and compression strength to make the pellets were evaluated by student's $t$ test. The method was considered robust due do not present statistically significant difference, since $t$ calculated value was lower than $t$ critical value, except for compression pressure, which means that caution must be taken at this point, as shown in Table 5.

Table 5. Results of Student's $t$ test for robustness of the spectrophotometry in the infrared region method for analysis of secnidazole.

\begin{tabular}{|c|c|c|c|c|}
\hline Conditions & $\begin{array}{c}\text { Absorbance } \\
\text { s with } \\
\text { normal } \\
\text { conditions * }\end{array}$ & $\begin{array}{c}\text { Absorbances } \\
\text { with changed } \\
\text { conditions * }\end{array}$ & $\begin{array}{c}\text { Test-F: } \\
\text { two } \\
\text { samples } \\
\text { for } \\
\text { variance } \\
\end{array}$ & $\begin{array}{c}\text { Test- } t \text { : two } \\
\text { samples } \\
\text { assuming } \\
\text { equal } \\
\text { variances } \\
\end{array}$ \\
\hline $\begin{array}{l}\text { Potassium } \\
\text { bromide } \\
\text { (BrK) mark }\end{array}$ & 0.425 & 0.410 & $\begin{array}{c}\text { F cal } \\
1.01< \\
19.0 \mathrm{~F} \\
\text { crit } \\
\\
p \text { value } \\
0.50> \\
0.05\end{array}$ & $\begin{array}{c}t \text { cal } 0.32 \\
<2.78 t \\
\text { crit } \\
p \text { value } \\
0.76> \\
0.05\end{array}$ \\
\hline $\begin{array}{l}\text { Compression } \\
\text { time }\end{array}$ & 0.425 & 0.444 & $\begin{array}{c}\mathrm{F} \mathrm{cal} \\
2.05< \\
19.0 \mathrm{~F} \\
\text { crit } \\
\\
p \text { value } \\
0.33> \\
0.05\end{array}$ & $\begin{array}{c}t \text { cal } 1.58 \\
<2.78 t \\
\text { crit } \\
p \text { value } \\
0.19> \\
0.05\end{array}$ \\
\hline $\begin{array}{l}\text { Compression } \\
\text { strength }\end{array}$ & 0.425 & 0.494 & $\begin{array}{c}\text { F cal } \\
7.04< \\
19.0 \mathrm{~F} \\
\text { crit } \\
p \text { value } \\
0.12> \\
0.05 \\
\end{array}$ & $\begin{array}{c}t \text { cal } 6.39 \\
>2.78 t \\
\text { crit } \\
p \text { value } \\
0.003< \\
0.05\end{array}$ \\
\hline
\end{tabular}

\section{Detection and Quantitation limits}

The limits of detection (LOD) and quantification (LOQ) were calculated to determine the sensitivity of the method. The value found for the LOD was $0.094 \mathrm{mg}$ and the LOQ was $0.284 \mathrm{mg}$, which indicates the reliability of the method for the determination and quantification of secnidazole tablets $1.000 \mathrm{mg}$ in the concentration range chosen.

\section{Conclusions}

In this work, it was validated a method using Fouriertransform infrared spectroscopy (FT-IR) for quantitation of secnidazole tablets. All validation parameters were satisfactory, indicating linearity, selectivity, precision, accuracy and robustness. In addition, the method presents advantagens over the existent methods for analysis of secnidazole due its simplicity of execution, low cost, absence of organic solvents, minimal preparation of samples, with low waste generation and high safety operator. Therefore, this method can be a great alternative in routine analysis for secnidazole tablets, as well as this study represents the possibility of application of FT-IR for quantification of drugs. 


\section{Acknowledgments}

The authors are grateful for pharmaceutical company EMS by donating the sample and working standard Secnidazol, FAPESP, CAPES and CNPq.

\section{References}

1. Tripathi, K.D. Essentials of Medical Pharmacology, $7^{\text {th }}$ Jaypee Brothers Medical Publishers, Bangladesh; 2013Bory S, Lubinsky P, Risterucci AM, Noyer JL, Grisoni M, Duval MF, et al. Patterns of introduction and diversification of Vanilla planifolia (Orchidaceae) in Reunion Island (Indian Ocean). Am J Bot. 2008;95: 805815.

2. Acar, J., Petitjean, O., Dubreuil, L. Le secnidazole, un nouveau 5-nitro-imidazoléSecnidazole, a new 5-nitroimidazole. Antibiotiques, 2005; 7:177-182. https://doi.org/10.1016/S1294-5501(05)80186-4.

3. Al-kaf, A.G.A., Gad kariem, A.E.R., Algaradi, A.A.S.A., \& Alssmani, T. Development and validation of an RPHPLC method for estimation of secnidazole and its degradation products in tablets. Glob J Pharmaceu Sci, 2016; 1: 1-9.

4. Alhalabi, Z., Al-khayat, M.A., Haidar, S. Separation and assay of antiprotozoal imidazole derivatives (metronidazole, tinidazole and secnidazole) by RPHPLC. Int. J Pharm Sci Rev Res, 2012; 13:13-18.

5. El Walily, A.F.M., Abdine, H.H., Razak, O.A., Zamel, S. Spectrophotometric and HPLC determination of secnidazole in pharmaceutical. J Pharm Biomed Anal, 2000; 22:887-897.

6. Farooqui, N.A., Smith, A.A., Sharma, H.K.; Manavalan, R. Analytical method development and validation of secnidazole tablets by RP-HPLC. J Pharm. Sci. \& Res, 2010; 2:412-416.

7. Reddy, K.S., Ramachandra, B., Naidu, N.V.S. Validation of RP-HPLC method for the estimation of secnidazole in bulk and its pharmaceutical dosage forms. Int J Sci Eng Res, 2014; 5:1250-1261.

8. Sharmin, T., Akter, M., Hossain, M.S. Analytical method development and validation of Secnidazole in the tablet dosage form by RP-HPLC method. Int Curr Pharm J, 2016; 5:41-44.

9. Suryawanshi, P.P., Khan, P.A., Abhyankar, M., Sonawane, S.S., Gide, P. A Validated StabilityIndicating Liquid Chromatographic Method for Secnidazole. J Innov Pharm Biol Sci, 2015; 2:45-52.
10.AOAC. Official Methods of Analysis of the Association of Official Analytical Chemists", in "Association of Official Analytical Chemists. Arlington; 1990. p. 890 896.

11.Saffaj, T., Charrouf, M., Abourriche, A., Abboud, Y., Bennamara, A., Berrada, M. Spectrophotometric determination of metronidazole and secnidazole in pharmaceutical preparations. Il Farm, 2004; 59:843-846. DOI:10.1016/j.farmac.2004.06.001.

12.Marcílio, M.R., Raiser, A.L., Fumagalli, L.P., Bonfilio, R., Andrighetti, C.R., Ribeiro, E.B. Determination and validation of secnidazole in tablets by UV spectrophotometric. Biosci J, 2017; 33:1351-1361.

13.Shovkova, O.V., Klimenko, L.Y., Kovalenko, S.M., Zhukova, T.V. Development and validation of UVspectrophotometric procedures for secnidazole quantitative determination, J Pharm Sci Res, 2017; 9:338-348.

14.Marco, B. A., Rechelo, B. S., Tótoli, E. G., Kogawa, A.C., Salgado, H.R.N. Evolution of green chemistry and its multidimensional impacts: A review. Saudi Pharm J, 2018; 2-8. https://doi.org/10.1016/j.jsps.2018.07.011.

15.Moreno, A.H., Salgado, H.R.N. Development and validation of the quantitative analysis of ceftazidime in powder for injection by infrared spectroscopy. Phys Chem, 2012; 2:6-11. DOI: 10.5923/j.pc.20120201.02.

16. Vieira, D.C.M., Ricarte, P.C., Salgado, H.R.N. Development and validation of the quantitative analysis of cefuroxime sodium in powder for injection by infrared spectroscopy. Adv Anal Chem, 2012; 2:80-87. DOI: 10.5923/j.aac.20120206.02.

17.Kogawa, A.C., Salgado, H.R.N. Development and validation of infrared spectroscopy method for the determination of darunavir in tablets. Phys Chem, 2013; 3:1-6. DOI:10.5923/j.pc.20130301.01.

18.Ali, M., Sherazi, S.T.H., Mahesar, S.A. Quantification of erythromycin in pharmaceutical formulation by transmission Fourier transform infrared spectroscopy. Arab J Chem, 2014; 7:1104-1109. https://doi.org/10.1016/j.arabjc.2012.09.003.2010.

19.Tótoli, E.G., Salgado, H.R.N. Development and validation of the quantitative analysis of ampicillin sodium in powder for injection by Fourier-transform infrared spectroscopy (FT-IR). Phys Chem, 2012; 2:103108.

20.Correa, J.C.R., Salgado, H.R.N. A plataform for designing quantitative infrared spectrophotometric method for drugs and pharmaceuticals analysis: a rediscover for an ecological and safer technique in the 
routine quality control laboratories. World J Pharm Pharm Sci, 2014; 3:2056-2059.Analíticos e Bioanalíticos, Resolução - RDC no 166, de 24 de julho de 2017.

21.Mallah, M.A., Sherazi, S.T.H., Bhanger, M.I., Mahesar, S.A., Bajeer, M.A. A rapid Fourier-transform infrared (FTIR) spectroscopic method for direct quantification of paracetamol content in solid pharmaceutical formulations. Spectrochim Acta A Mol Biomol Spectrosc, 2015; 141:64-70. DOI: 10.1016/j.saa.2015.01.036.

22.Marco, B. A., Salgado, H. R. N. Development and validation of an innovative method for the determination of cefadroxil monohydrate in capsules. Phys Chem, 2016; 6:67-74. DOI: 10.5923/j.pc.20160603.02.

23.Natori, J.S.H., Tótoli, E.G., Salgado, H.R.N. Development and validation of a green analytical method for the determination of norfloxacin in raw material by FTIR spectrophotometry. J AOAC Int, 2016; 99:15331536. https://doi.org/10.5740/jaoacint.16-0177

24. Tótoli, E.G., Salgado, H.R.N. Fourier-transform infrared (FTIR) spectrophotometry: An ecofriendly method for the analysis of injectable daptomycin. J AOAC Int, 2017; 100:1569-1576. https://doi.org/10.5740/jaoacint.170067.

25.Trindade, M.T., Salgado, H.R.N. Development and validation of a modern and stability-indicating method for the quantification of ceftriaxone sodium in powder for injection by infrared spectroscopy. Phys Chem, 2017; 48:55-62. DOI: 10.5923/j.pc.20170703.01.

26.Consortti, L.P., Salgado, H.R.N. Green Method for Quantification of Sodium Cefotaxime in Lyophilized Powder by Infrared Spectroscopy. J Pharm Sci Emerg Drugs, 2017; 5:1-7. DOI: 10.4172/2380-9477.1000118.

27.Kogawa, A.C., Salgado, H.R.N. Spectrophotometry in infrared region: A new, low cost and green way to analyze tablets of rifaximin. Curr Pharm Anal, 2018; 14:108-115.

DOI:

$10.2174 / 1573412913666161213103657$.

28.Pavia, D.L., Lampman, G.M., Kriz, G.S., Vyvyan J.R. Introduction to spectroscopy, $4^{\text {th }}$, Cengage Learning: Belmont; 2008.

29. Brazilian Pharmacopoeia, ANVISA: Brasília; $5^{\text {th }}, 2010$.

30.Bonfilio, R., Araújo, M.B., \& Salgado, H.R.N. Recent applications of analytical techniques for quantitative pharmaceutical analysis: a review. WSEAS Trans Bio Biom, 2010; 7:316-338.
31.RDC no 899 of May 29: Guide to validation of analytical and Bioanalytical methods. National Health Surveillance Agency, Brasilia [serial online] 2003 [cited 2018 Jul 30]. Available from:

URL:http://portal.anvisa.gov.br/documents/10181/27183 76/RE_899_2003_COMP.pdf/ff6fdc6b-3ad1-4d0f-9af2$36254 \overline{2} 2 \mathrm{e} 6 \overline{\mathrm{f}} \mathrm{b} \mathrm{b}$.

32.RDC $\mathrm{n}^{\circ} 17$ of April 16: Provides on Pharmaceutical Good Manufacturing Practices. National Health Surveillance Agency, Brasilia. [serial online] 2010 [cited 2018 Jul 30]. Available from: URL:http://portal.anvisa.gov.br/documents/33880/25680 70/res0017_16_04_2010.pdf/b9a8a293-f04c-45d1-ad4c$19 \mathrm{e} 3 \mathrm{e} 8 \mathrm{bee} \overline{\mathrm{fa}}$.

33.Al-Kaf, A.G.A.; Gad Kariem, A. Er.; Algaradi, A.A.S.A. \& Alssmani, T. Development and validation of an RPHPLC method for estimation of secnidazole and its degradation products in tablets. Global J Pharm Pharm Sci, 2016; 1 .

34.Baraka, M. M.; Elsadek, M.E. \& Ibrahim, A.M. HPLC method for the simultaneous determination of secnidazole, omeprazole and amoxicillin mixture in pure forms and pharmaceutical formulations. Asian J Pharm Anal Med Chem, 2014; 2:197-207.

35. Shovkova, O.V.; Klimenko, L.Y.; Kovalenko, S.M. \& Zhukova, T.V. Development and validation of UVspectrophotometric procedures for secnidazole quantitative determination. J Pharm Sci Res, 2017; 9:338-348.

36.Nascimento, A.C.; Perna, R.F.; Cremasco, M.A. \& Santana, C.C. Enantioseparation of secnidazole by highperformance liquid chromatography using amylosebased stationary phase. Adsorp Sci Technol, 2012; 30:739-750, 2012.

37.Meng, X.; Bai, H.; Zhang, O.; Chen, Y.; Ma, H.; Li, J. \& Ma, Q. Simultaneous determination of 15 nitroimidazoles in cosmetics by HPLC coupled with electrospray ionization-tandem mass spectrometry. J AOAC Int, 2014; 97:1538-1545, 2014.

38. Validation of analytical procedures: text and methodology Q2 (R1) International Harmonised Tripartite Guideline (ICH), Geneva. [serial online] 2005 [cited 2018 Jul 30]. Available from: URL:https://www.ich.org/fileadmin/Public_Web_Site/IC H_Products/Guidelines/Quality/Q2_R1/Step4/ Q $\overline{2}$ _R1_Guideline.pdf 